\title{
The Test of Industrial Environmental Kuznets Curve Hypothesis in Jiangsu Province
}

\author{
Zhoumu Yang ${ }^{1,2, *}$,Wenping Wang ${ }^{1}$, Yibo Yang ${ }^{3}$ \\ ${ }^{1}$ School of Economics and Management, Southeast University, P.R.China, 211189 \\ ${ }^{2}$ School of Mathematics and Statistics, Nanjing University of Information Science and Technology, \\ P.R.China, 210044
}

${ }^{3}$ School of Physics and Optoelectronic Engineering, Nanjing University of Information Science and Technology, P.R.China, 210044

Yangzhoumu1978@163.com

\begin{abstract}
Based on the theory of Environmental Kuznets Curve (EKC), this paper sets up a regression model between economic development and industrial pollution according to the data of per capita GDP and "three industrial wastes" in Jiangsu Province over the period of 1999 to 2012.Regression analysis show that there is no obvious EKC relationship between the industrial effluents emissions and per capita GDP in Jiangsu province. There exist a "N" curve relationship between industrial waste gas emissions and per capita GDP. The first turning point is located at per capital GDP ¥ 23707 during 2004 and 2005, after then, industrial waste gas emissions showed a trend of decline. The second turning point appeared during the year of 2009 and 2010, which is located at per capital GDP $¥ 49513$, and then the trend turned to rise again. Meanwhile, there exist a "N" curve relationship between industrial solid wastes and per capita GDP. The first turning point is located at per capital GDP ¥22975 during 2004 and 2005, after that, industrial solid wastes showed a trend of decline. The second turning point appeared during the year of 2011 and 2012, which is located at per capital GDP $¥ 66507$, then the trend turned to rise again, and this trend will not change in the short term. Transforming and upgrading from factor-driven and capital-driven to innovation-driven is important for
\end{abstract} economic transformation and upgrading in Jiangsu.

KEYWORD: EKC; three industrial wastes; per capita GDP; economic development; environment pollution

\section{INTRODUCTION}

With the collapse of resources and deterioration of environment, research on the relationship between the economy and environment has been widespread concerned among scholars of different fields as an important social science problem. EKC theory was first mentioned in the research on the relationship between environmental change and economic growth. In 1991, Grossman and Kruger (1991) analyzed the data of urban air quality estimated by the Global Environmental Monitoring System (GEMS), finding that the inversed-U shaped relationship existed with respect to sulfur dioxide and soot emission. Then, as the leaders, Grossman and Kruger(1995) empirically studied the relationship between economic development and environment: in the early stage, environmental quality is easily deteriorated with the process of economic development, when the economy develops to a certain level, deterioration of the environment will reach its peak, after that, with the increase of per capita income and the development of economy, environmental pollution will get ease because of structure effect and technology effect, and then environment quality will be improved gradually (Dimitra Kaika and Efthimios Zervas,2013).After Grossman and Kruger, some empirical studies showed that the inverted- $U$ shaped relationship between most indicators of environmental quality and per capita income does exist,on the other hand, the conclusions are controversial (Kijima, 2011; Bimonte, 2012). Different from most scholars at that time, Panayotou (1993) added the population variable into the influence factors, regarding environmental pollutants emissions per person as the pollution indicator. Panayotou selected the data of per person emission of sulfur dioxide, nitrogen oxide and suspended solids and per capita GDP in 54 countries to analyze the relation between environment and economy. Results showed that there is inversed- $U$ relationship between the three kinds of pollutants and per capita GDP. This relation curve is shaped like a inverted " $U$ ", in similar shape 
with the Kuznets Curve, which represents the evolution of income equality (Kuznets,1955). Therefore, Panayotou named the relation curve of economy-environment as "Environmental Kuznets Curve" firstly.

Located in the Yangtze River delta, Jiangsu Province proposed the new social and economic development objects as "two leadings". Place the positive ecological construction and environmental protection in the priority of the overall situation of economic and social development. To this end, we need to find out the relationship and dynamic evolutionary rules between economic growth and environmental quality, in order to providing decision-making reference for accelerating the transformation and upgrading of industrial structure in Jiangsu Province.

\section{THREE INDUSTRIAL WASTES AND PER CAPITA GDP IN JIANGSU PROVINCE}

\subsection{Sources of data}

The data required in this paper was taken from 《Statistical yearbook of Jiangsu》during 2000 and 2013.

\subsection{Descriptive statistics of data}

The trends of "three industrial wastes" and per capita GDP during the period of 1998 and 2012 are presented in Figure1-3.

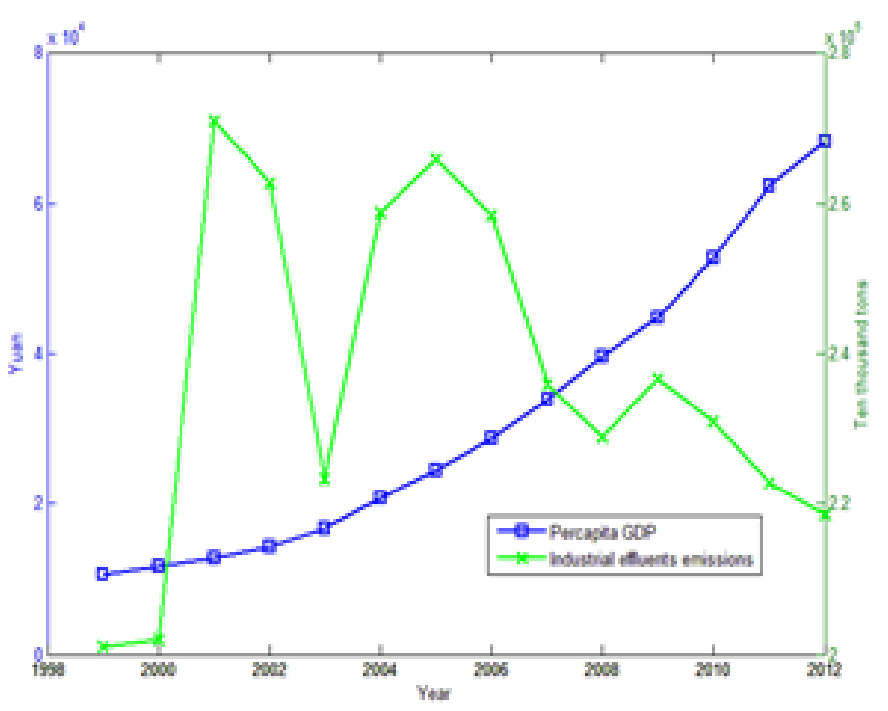

Figure 1. Industrial effluents emissions and per capita GDP

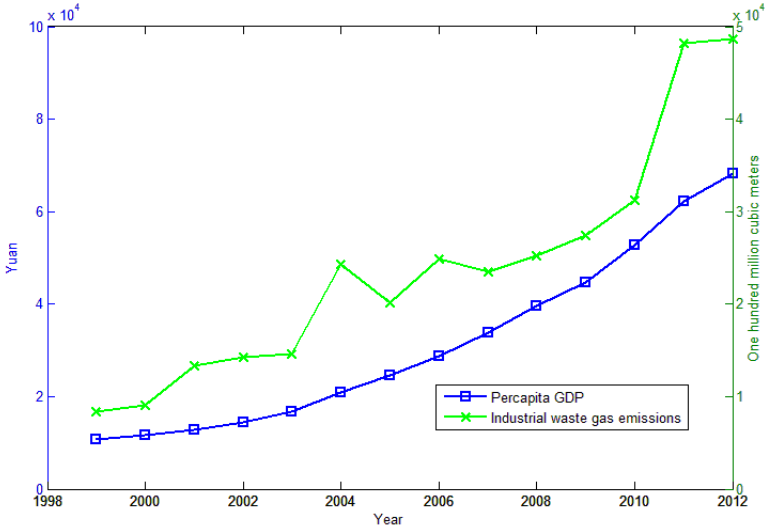

Figure2. Industrial waste gas emissions and per capita GDP

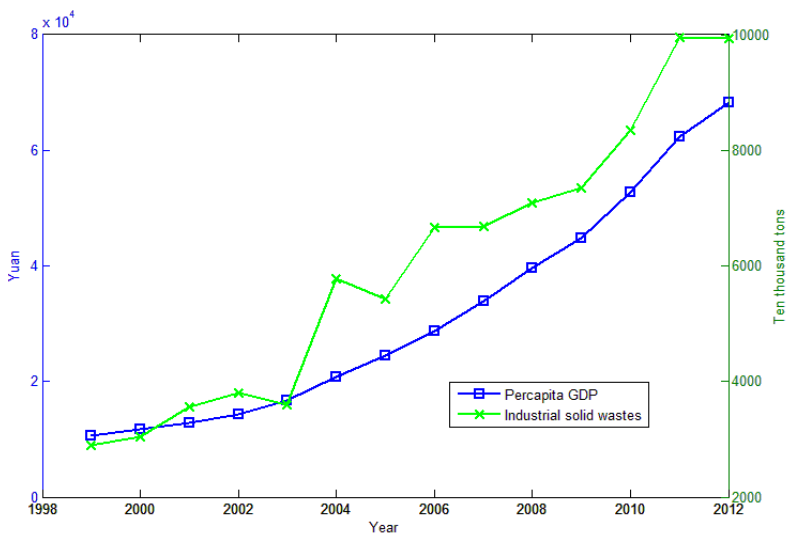

Figure 3. Industrial solid wastes and per capita GDP

\section{THEORETICAL MODEL AND THE RESULT OF DATA FITTING}

\subsection{Model}

Based on Dimitra Kaika (2013), we use the cubi c regression model

$y_{i t}=\alpha_{i}+\beta_{1} x_{i t}+\beta_{2} x_{i t}{ }^{2}+\beta_{3} x_{i t}{ }^{3}+\beta_{4} z_{i t}+\mu_{i t}, i=1,2, \cdots, N . t=1,2, \cdots, T$.

In Eq. (1), $y_{i t}$ is the depended variable of environmental degradation, $x_{i t}$ is the independent variable of income, $z_{i t}$ reflects other variables that may affect $y_{i t}, \alpha_{i}$ is the constant term, and $\beta_{i}$ are the estimated coefficients of the explanatory variables, $\mu_{i t}$ represents the error term.

\subsection{Results of fitting}

According to Eq. (1), we can construct the regression model between Per capita GDP and three industrial wastes, as shown in the following tables. The relationship between emissions and per capita GDP discussed above is represented in Fig4-6. 
Table 1. Industrial Effluents Model Summary and Parameter Estimates

\begin{tabular}{|c|c|c|c|c|c|c|c|c|}
\hline \multicolumn{4}{|c|}{ Model Summary } & \multicolumn{4}{c|}{ Parameter Estimates } \\
\hline $\mathrm{R}^{2}$ & $\mathrm{~F}$ & $\mathrm{df1}$ & $\mathrm{df} 2$ & Sig. & $\alpha$ & $\beta_{1}$ & $\beta_{2}$ & $\beta_{3}$ \\
\hline .361 & 1.882 & 3 & 10 & .197 & $1.410 \mathrm{E} 5$ & 10.306 & .000 & $2.184 \mathrm{E}-9$ \\
\hline
\end{tabular}

* Dependent Variable: Effluents

** The independent variable is Per capita GDP.

Table2. Industrial Waste Gas Model Summary and Parameter Estimates

\begin{tabular}{|c|c|c|c|c|c|c|c|c|}
\hline \multicolumn{4}{|c|}{ Model Summary } & \multicolumn{4}{c|}{ Parameter Estimates } \\
\hline $\mathrm{R}^{2}$ & $\mathrm{~F}$ & $\mathrm{df} 1$ & $\mathrm{df} 2$ & Sig. & $\alpha$ & $\beta_{1}$ & $\beta_{2}$ & $\beta_{3}$ \\
\hline .956 & 71.59 & 3 & 10 & .000 & $-1.101 \mathrm{E} 4$ & 2.474 & $-6.011 \mathrm{E}-5$ & $5.473 \mathrm{E}-10$ \\
\hline
\end{tabular}

* Dependent Variable: Gas

** The independent variable is Per capita GDP.

Table3. Industrial Solid Wastes Model Summary and Parameter Estimates

\begin{tabular}{|c|c|c|c|c|c|c|c|c|}
\hline \multicolumn{4}{|c|}{ Model Summary } & \multicolumn{4}{c|}{ Parameter Estimates } \\
\hline $\mathrm{R}^{2}$ & $\mathrm{~F}$ & $\mathrm{df} 1$ & $\mathrm{df} 2$ & Sig. & $\alpha$ & $\beta_{1}$ & $\beta_{2}$ & $\beta_{3}$ \\
\hline .975 & 129.6 & 3 & 10 & .000 & -769.758 & .411 & $-7.428 \mathrm{E}-6$ & $5.534 \mathrm{E}-11$ \\
\hline
\end{tabular}

* Dependent Variable: Solid

** The independent variable is Per capita GDP.

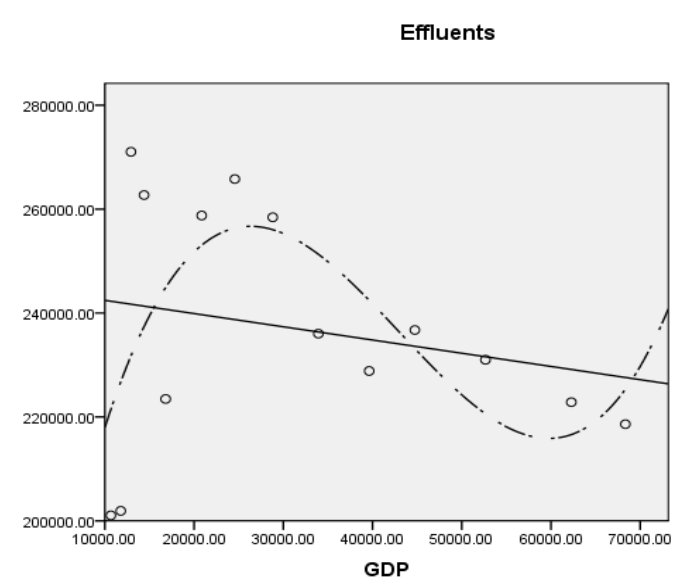

Fig. 4. Industrial effluents emissions

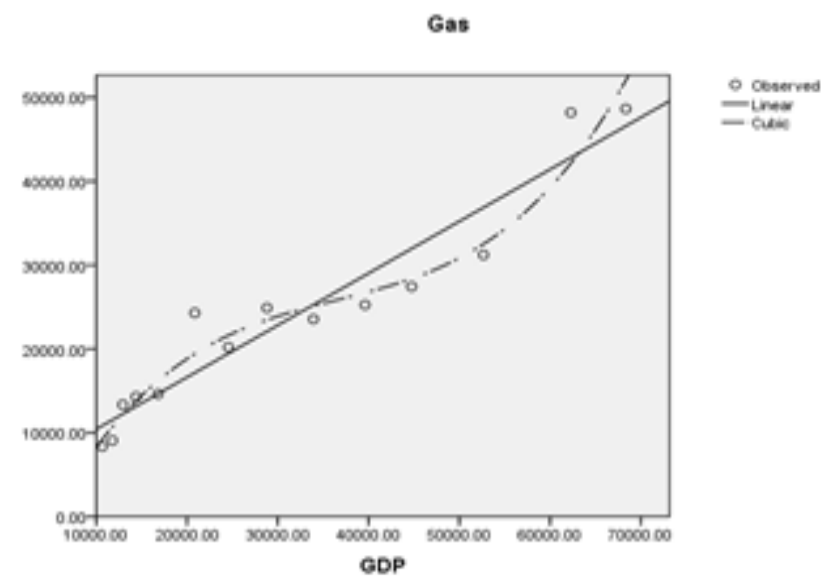

Fig. 5. Industrial waste gas emissions

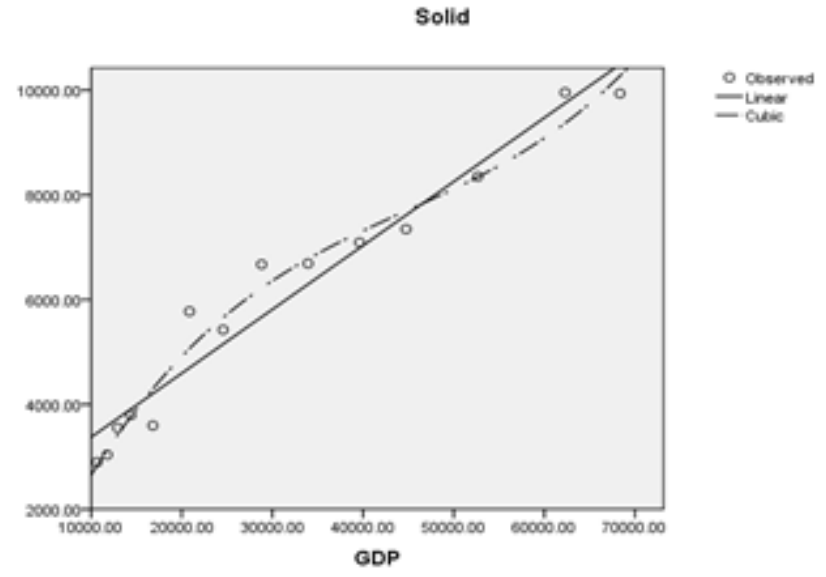

Fig. 6. Industrial solid wastes

\section{CONCLUSIONS}

We can see from tables above, for T-test's sig $=0.197$, there is no obvious EKC relationship between the industrial effluents emissions and per capita GDP in Jiangsu province.

For $\quad \beta_{1}>0, \beta_{2}<0, \beta_{3}>0$ and T-test's sig $=0.000$, there exist a " $\mathrm{N}$ " curve relationship between industrial waste gas emissions and per capita GDP. Through calculating the first order derivative, we can find that the first turning point is located at per capital GDP $¥ 23707$ during 2004 and 2005, after the first turning point appearing between 2004 and 2005, industrial waste gas emissions showed a trend of decline. The second 
turning point appeared during the year of 2009 and 2010, which is located at per capital GDP $¥ 49513$, and then the trend turned to rise again.

For the same reason,there exist a " $N$ " curve relationship between industrial solid wastes and per capita GDP. The first turning point is located at per capital GDP ¥22975 during 2004 and 2005, after that, industrial solid wastes showed a trend of decline. The second turning point appeared during the year of 2011 and 2012, which is located at per capital GDP $¥ 66507$, and then the trend turned to rise again.

All in all, economic development in Jiangsu is still, to some extent, at the expenses of sacrificing environment. Emissions are now on the rise trend, and this trend will not change in the short term. Transforming and upgrading from factor-driven and capital-driven to innovation-driven is important for economic transformation and upgrading in Jiangsu.

\section{ACKNOWLEDGMENT}

This research was financially supported by Major Bidding Project of the National Social Science Foundation of China (Grant No. 12\&ZD207), the National Natural Science Foundation of China (Grant No. 70973017, 71172044, 71273047), Research Fund for the Doctoral Program of Higher Education of China (Grant No. 20120092110039), Major Project of Philosophy and Social Science
Research of the Higher Education Institutions of Jiangsu Province (Grant No. 2014ZDAXM002).

\section{REFERENCES}

[1] Bimonte, S. 2012. Public goods, environmental quality and the EKC - the 'unsaid' of the intensity of use indices. International Journal of Sustainable Economy 4(2): 167180.

[2] Dimitra Kaika \& Efthimios Zervas. 2013. The Environmental Kuznets Curve (EKC) theory-Part A: Concept, causes and the CO2 emissions case. Energy Policy 62:1392-1402.

[3] Grossman, G.M. \& Krueger, A. B. 1991. Environmental impacts of a North American Free Trade Agreement. National Bureau of Economic Research Working Paper 3914, NBER, Cambridge MA.

[4] Grossman, G.M. \& Krueger, A.B. 1995. Economic growth and the environment.The Quarterly Journal of Economics 110(2), 353-377.

[5] Kijima, M. \& Nishide, K. \& Ohyama, A. 2011. EKC-type transitions and environmental policy under pollutant uncertainty and cost irreversibility. Journal of Economic Dynamics and Control 35(5): 746-763.

[6] Kuznets, S. 1955. Economic growth and income inequality. American Economic Review 45:1-28.

[7] Panayotou, T. 1993. Empirical tests and policy analysis of environmental degradation at different stages of economic development. Geneva: Working paper WP 238, Technology and Employment Programme, Internationl Labor Office. 